\title{
The two-way link between diabetes mellitus and periodontal disease: Medical health care professional's clinical practice
}

\author{
ALLAUDDIN SIDDIQI ${ }^{1}$ and Sobia Zafar $^{2}$ \\ ${ }^{1}$ Griffith University School of Dentistry and Oral Health \\ ${ }^{2}$ The University of Queensland School of Dentistry
}

January 2, 2021

\begin{abstract}
Background: Diabetes mellitus and periodontal disease are global epidemic ailment with severe health consequences. The literature regarding medical-healthcare professionals' knowledge, attitude, and practices regarding periodontal-diabetes disease link from Australia is missing. Methods: A convenience sample of medical-healthcare professionals participated in the study to complete an 18-item questionnaire. An online survey was designed to investigate the knowledge and understanding of the periodontal disease (gingivitis and periodontitis) and the link between periodontal disease and diabetes mellitus. Results: A total of 46 medical professionals completed the survey. The results of the pilot study demonstrated higher understanding and awareness of the bidirectional relationship between diabetes mellitus and periodontal disease among this cohort of medical professionals. The majority of the medical practitioners (89\%) knew that the glycemic index of persons living with diabetes (having periodontal disease) could be improved by providing periodontal therapy. Conclusion: It can be concluded that the investigated cohort is aware of the association between periodontal disease and diabetes mellitus. However, this knowledge is not reflected in their clinical practice resulting in a low frequency of referral and communication with the dentist. It is the time medical professionals should realise the fact that "No health without oral health".
\end{abstract}

\section{Hosted file}

Manuscript - Medical professionals - IJCP (main document).pdf available at https: //authorea.com/users/386668/articles/502125-the-two-way-link-between-diabetes-mellitusand-periodontal-disease-medical-health-care-professional-s-clinical-practice

\section{Hosted file}

Table 1.pdf available at https://authorea.com/users/386668/articles/502125-the-two-way-1inkbetween-diabetes-mellitus-and-periodontal-disease-medical-health-care-professional-sclinical-practice

\section{Hosted file}

Table 2.pdf available at https://authorea.com/users/386668/articles/502125-the-two-way-linkbetween-diabetes-mellitus-and-periodontal-disease-medical-health-care-professional-sclinical-practice

\section{Hosted file}

Table 3.pdf available at https://authorea.com/users/386668/articles/502125-the-two-way-linkbetween-diabetes-mellitus-and-periodontal-disease-medical-health-care-professional-sclinical-practice

\section{Hosted file}


Table 4.pdf available at https://authorea.com/users/386668/articles/502125-the-two-way-linkbetween-diabetes-mellitus-and-periodontal-disease-medical-health-care-professional-sclinical-practice 